\title{
Review Article \\ Current Understanding on Antihepatocarcinoma Effects of Xiao Chai Hu Tang and Its Constituents
}

\author{
Ningning Zheng, ${ }^{1}$ Jianye Dai, ${ }^{1}$ Huijuan Cao, ${ }^{1}$ Shujun Sun, ${ }^{1}$ Junwei Fang, ${ }^{1}$ Qianhua Li, \\ Shibing Su, ${ }^{2}$ Yongyu Zhang, ${ }^{1}$ Mingfeng Qiu, ${ }^{3}$ and Shuang Huang ${ }^{4}$ \\ ${ }^{1}$ Center for Traditional Chinese Medicine and Systems Biology, Shanghai University of Traditional Chinese Medicine, \\ Shanghai 201203, China \\ ${ }^{2}$ Research Center for Traditional Chinese Medicine Complexity System, Shanghai University of Traditional Chinese Medicine, \\ Shanghai 201203, China \\ ${ }^{3}$ School of Pharmacy, Shanghai Jiao Tong University, Shanghai 200240, China \\ ${ }^{4}$ Department of Biochemistry and Molecular Biology, Medical College of Georgia, Georgia Health Sciences University, \\ Augusta, GA 30907, USA
}

Correspondence should be addressed to Yongyu Zhang; dryyz@sina.com and Mingfeng Qiu; mfqiu@sjtu.edu.cn

Received 3 January 2013; Revised 25 April 2013; Accepted 27 May 2013

Academic Editor: Rong Zeng

Copyright (c) 2013 Ningning Zheng et al. This is an open access article distributed under the Creative Commons Attribution License, which permits unrestricted use, distribution, and reproduction in any medium, provided the original work is properly cited.

Xiao Chai Hu Tang (XCHT), a compound formula originally recorded in an ancient Chinese medical book Shanghanlun, has been used to treat chronic liver diseases for a long period of time in China. Although extensive studies have been demonstrated the efficacy of this formula to treat chronic hepatitis, hepatic fibrosis, and hepatocarcinoma, how it works against these diseases still awaits full understanding. Here, we firstly present an overview arranging from the entire formula to mechanism studies of single herb in XCHT and their active components, from a new perspective of "separation study," and we tried our best to both detailedly and systematically organize the antihepatocarcinoma effects of it, hoping that the review will facilitate the strive on elucidating how $\mathrm{XCHT}$ elicits its antihepatocarcinoma role.

\section{Introduction}

The American Cancer Society's estimation for primary liver and bile duct cancers in the United States for 2013 is about 30,640 new cases and 21,670 deaths from these cancers. Liver cancer is even more common in sub-Saharan Africa and Southeast Asia and currently is the most common type of cancers in many countries in these regions [1]. Among various types of liver cancer, hepatocellular carcinoma (HCC) is the most common one, and the majority of them are associated with chronic hepatitis B virus (HBV) or hepatitis C virus (HCV) infections $[2,3]$. Chronic viral hepatitis, chemicalinduced liver damage, could cause liver fibrosis and cirrhosis, finally leading to liver cancer.

Compound herbal formulas have been used to treat cancers, and many of them have shown the promise to improve the life of cancer patients [4-6]. These compound formulas are usually made of several Chinese medicinal herbs and suppress tumor progression by multiple mechanisms [7]. One of them is called Xiao Chai Hu Tang (XCHT, Sho-saiko-to, in Japanese) that was originally recorded in ancient Chinese medical book Shanghanlun. It consists of seven medicinal herbs (Bupleurum falcatum, Scutellaria baicalensis, Panax ginseng, Zizyphus jujube, Pinellia ternate, Zingiber officinale, and Glycyrrhiza glabra) and is currently used to treat chronic liver diseases especially chronic hepatitis [8-11]. Data from recent clinical trials convincingly show that XCHT can prevent the development of HCC in patients with cirrhosis, particularly those without HBs antigen [9]. Experimental studies further indicate that XCHT may achieve its effect by reducing hepatocyte necrosis and enhancing liver function. Moreover, XCHT has also been shown to exhibit various anticarcinogenic properties such as induction of apoptosis and suppression of invasion $[12,13]$. 
TABLE 1: Some clinical trials of XCHT.

\begin{tabular}{|c|c|c|c|}
\hline Author; year & Cases & Research design & Results \\
\hline Hirayama et al. [8]; 1989 & $\begin{array}{l}222 \text { chronic } \\
\text { hepatitis subjects }\end{array}$ & $\begin{array}{l}\text { Double-blind, } \\
\text { multicenter }\end{array}$ & $\begin{array}{l}\text { The difference of the mean value of AST and ALT between } \\
\text { the XCHT group and placebo group was significant; a } \\
\text { tendency towards a decrease of HBeAg and an increase of } \\
\text { anti-HBe antibodies was also observed in patients with } \\
\text { chronic active type B hepatitis }\end{array}$ \\
\hline Oka et al. [9]; 1995 & $\begin{array}{l}260 \text { cirrhotic } \\
\text { subjects }\end{array}$ & Randomized, controlled & $\begin{array}{l}\text { The cumulative incidence curve for } 5 \text { years of the trial group } \\
\text { (XCHT combined with conventional drugs) was lower while } \\
\text { the survival curve for } 5 \text { years of the trial group was higher } \\
\text { compared with control group (conventional drugs). The } \\
\text { difference was significant for patients without HBs antigen }\end{array}$ \\
\hline Deng et al. [11]; 2011 & $\begin{array}{c}24 \text { chronic } \\
\text { hepatitis C subjects }\end{array}$ & $\begin{array}{c}\text { A single arm phase II } \\
\text { study }\end{array}$ & $\begin{array}{l}\text { Improvement of AST ( } 16 \text { subjects) and ALT (18 subjects) was } \\
\text { observed; } 9 \text { subjects showed improvement in histology } \\
\text { activity index scores }\end{array}$ \\
\hline Bo and Du [14]; 2006 & $\begin{array}{c}96 \text { chronic } \\
\text { hepatitis B subjects }\end{array}$ & Randomized, controlled & $\begin{array}{l}\text { Experiment group (XCHT combined with } \alpha \text {-interferon) } \\
\text { showed better effect in aspects of ALT improvement and } \\
\text { HBeAg negative transform than } \alpha \text {-interferon treatment } \\
\text { group }\end{array}$ \\
\hline Li et al. [15]; 2001 & $\begin{array}{c}110 \text { chronic } \\
\text { hepatitis B subjects }\end{array}$ & Randomized, controlled & $\begin{array}{l}\text { ALT, total bilirubin, and serum liver fibrosis indexes were } \\
\text { decreased in combination treatment group (XCHT and } \\
\gamma \text {-interferon) and the difference was significant compared } \\
\text { with } \gamma \text {-interferon treatment group }\end{array}$ \\
\hline Sun et al. [16]; 2003 & $\begin{array}{l}94 \text { chronic } \\
\text { hepatitis B with } \\
\text { fibrosis subjects }\end{array}$ & Randomized, controlled & $\begin{array}{l}\text { The liver function was improved and serum liver fibrosis } \\
\text { indexes were decreased; the difference was significant } \\
\text { between combination treatment group (XCHT and } \\
\text { oxymatrine) and controlled group (reduced glutathione and } \\
\text { vitamin treatment) }\end{array}$ \\
\hline Wu [17]; 2009 & $\begin{array}{l}142 \text { chronic } \\
\text { hepatitis B with } \\
\text { cirrhosis subjects }\end{array}$ & Randomized, controlled & $\begin{array}{l}\text { The liver function was improved and serum liver fibrosis } \\
\text { indexes were decreased; the difference was significant } \\
\text { between XCHT treatment group and controlled group } \\
\text { (hepatic protective drug and antifibrosis drug treatment) }\end{array}$ \\
\hline
\end{tabular}

Chinese herbal medicines are usually used to counteract tumor progression by a formula of multiple herbs rather than a single one. Unfortunately, studies have been mainly focused on defining the mechanism of a single herb or its ingredients. As each herb in XCHT can potentially exert its effect in a distinct mechanism, a formula of seven herbs is expected to reach its full effect by targeting multipathways and multitargets. So we firstly introduce a new perspective of "separation study," that is, from the entire formula to single herb and their active components, both detailedly and systematically organize the antihepatocarcinoma effects of $\mathrm{XCHT}$. We hope that this review will help XCHT to receive its well-deserved global recognition and to be better appreciated for its clinical use to treat liver cancers.

\section{Xiao Chai Hu Tang (XCHT)}

2.1. Clinical Trials of XCHT. XCHT has long been used in clinical trials for the study and treatment of liver diseases. Some XCHT clinical trials (including the clinical trials mentioned above and some other trials [14-17] conducted in China) are summarized in Table 1.

2.2. Experimental Studies of XCHT. The potential tumorsuppressing effect of XCHT was reported in 1994, in which
XCHT was found capable of inhibiting the proliferation of KIM-1, a human hepatocellular carcinoma cell line and KMC1, a cholangiocarcinoma cell line [18]. Later on, XCHT was shown to diminish not only the growth of various cancer cell lines but also in vivo tumor outgrowth in xenograft model [19-21].

In addition to its tumor-suppressing role, Chang et al. studied the effect of XCHT on HBV replication in HepG2 2.2.15 cell model [22]. Their study showed that XCHT reduced $\mathrm{HBV}$ production and $\mathrm{HBeAg}$ expression without altering the level of HBsAg. Although XCHT can also block Coxsackie B type 1 virus infection in CCFS-1 cells through the induction of Type I interferon expression [23], the mechanism responsible for XCHT-mediated suppression of HBV production awaits being defined.

Hepatic fibrosis and liver cirrhosis result from wound healing of ongoing hepatocellular damage caused by chronic liver injuries [13]. Most of HCCs ensue in a cirrhotic liver [24]. Kusunose et al. created an animal model that reflected various stage-liver injuries and used this model to determine under what condition XCHT extract could improve hepatic inflammation and fibrosis [25]. Their study found that the ability of XCHT extract was limited to a certain degree which was expressed by levels of respective parameters (AST, ALT, TGF- $\beta$, hydroxyproline, and the ratio of liver fibrosis 


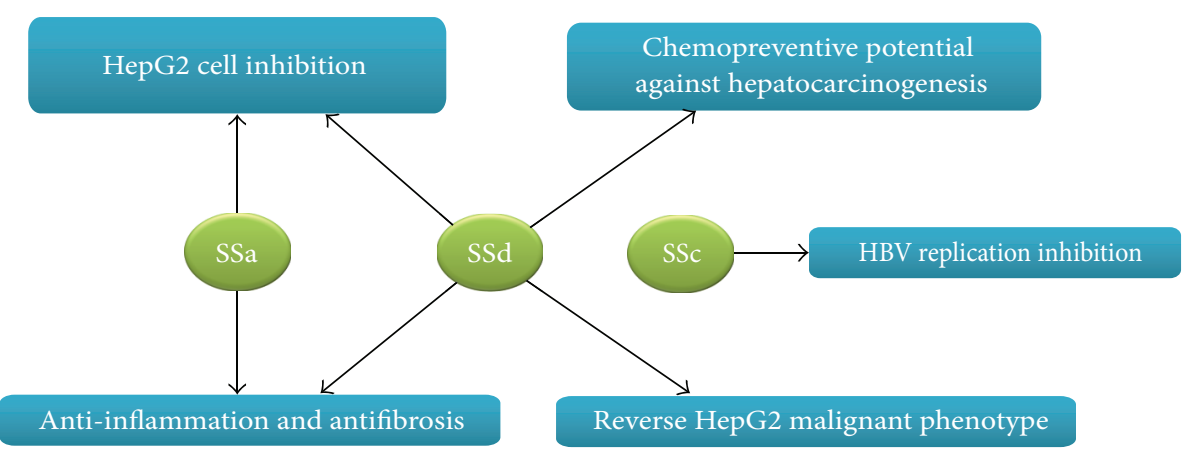

FIGURE 1: Antitumorigenesis effect of active components in Bupleuri radix.

area). Chen et al. later elucidated the mechanism pertinent to XCHT's antifibrosis capability by assessing its effect on the expression of those growth factors and cytokines important for the activation of hepatic stellate cells (HSCs) [26]. They showed that XCHT downregulated the levels of stellate cell activation-essential TGF $\beta 1$, platelet derived growth factor (PDGF), and IL-1 $\beta$ while stimulated the production of stellate cell activation-inhibitory $\mathrm{TNF} \alpha$.

\section{Individual Herbs and Active Components in XCHT}

In TCM, XCHT is a classical formula to treat the typhoid lesser yang syndrome. The compound prescription has its formulating principle. Among the seven herbs included in XCHT, Bupleurum falcatum is the "monarch" and Scutellaria baicalensis is the "minister," which are the principal herbs in this formula. Panax ginseng, Zizyphus jujube, Pinellia ternate, and Zingiber officinale are the "assistant" while Glycyrrhiza glabra is the "guide" [27]. Bupleurum has the effect of upraising and dispersing the pathogen and soothing the meridian Qi. Scutellaria has the effect of clearing and down-sending heat with bitter-cold, as well as eliminating the heat. Panax ginseng and Zizyphus jujube work compatibly to tonify Qi and fortify the spleen, thus strengthening the body and eliminate pathogens; Pinellia ternate and Zingiber officinale work together to regulate the stomach Qi and prevent vomit; and the "guide" Glycyrrhiza glabra is used to harmonize the other herbs. Nowadays, XCHT is used to treat common cold, chronic hepatitis, hepatic cirrhosis, bile reflux gastritis, cholecystitis, acute pancreatitis, and so forth, which belong to lesser yang syndrome.

3.1. Bupleurum falcatum. The root of Bupleurum falcatum L. (Umbelliferae), especially B. chinense from mainland China and B. falcatum from Japan [28, 29], is also called Bupleuri Radix ((BR) Chaihu, in Chinese and Saiko in Japanese) and is one of the principal herbs in XCHT. Early study examined the hepatoprotective effect of several BR extracts with dimethylnitrosamine- (DMN-) induced hepatic fibrosis rat model and these extracts appeared to prevent fibrosis by improving liver function and modulating the levels of relevant cytokines [29]. Recent studies also suggest BR extracts as potent antioxidant agents because they are able to decrease Lthyroxine-induced hypothyroidism and to enhance the liver antioxidant defense systems [30].

Some saikosaponins, which are the active ingredients of $\mathrm{BR}$, have been found to suppress hepatic fibrosis [31, 32], hepatocarcinoma [33-36], and HBV infection [37] and improve chemotherapy [38]. The different mechanisms through which saikosaponins suppressed hepatocarcinoma were summarized in Figure 1. Saikosaponin a (SSa) was shown to effectively inhibit $\mathrm{CCl}_{4}$-induced liver inflammation and fibrosis in SD rats by simultaneously blocking the production of hepatic proinflammatory cytokines/growth factors (TGF $\beta 1$ and hydroxyproline) and increasing the expression of antiinflammatory cytokine IL-10 [31]. Saikosaponin d (SSd) was found to suppress hepatic fibrosis through the downregulation of TNF- $\alpha$, IL- 6 , and NF- $\kappa$ B activities [32]. SSa may inhibit HepG2 growth by increasing the levels of p-15INK4a and p-16INK4b (cyclin-dependent kinase inhibitors) in a protein kinase $\mathrm{C}$ (PKC) [33] and/or extracellular signalregulated kinase (ERK) signaling pathway-dependent manner [34]. SSd markedly reduced the liver nodule, tumor cell invasion while increased cellular atypia in xenograft model [35]. It appeared that SSd exerted its action by diminishing the expression of highly expressed cyclooxygenase 2 (COX-2) and CCAAT/enhancer-binding protein $\beta(\mathrm{C} / \mathrm{EBP} \beta)$ in tumor cells and macrophages of liver tumors [35]. In a study reported by Zhu et al. [36], SSd was shown capable of reversing the malignant phenotype of HepG2 cells. SSd-treated HepG2 cells grew and migrated at slower rate, had decreased volume ratios of nucleus to plasma and small round cell shape. At molecular level, SSd decreased the level of alphafetoprotein (AFP) and enhanced the expression of cell cycle inhibitor p27. Moreover, Chiang et al. showed that HBVcontaining human hepatoma cells (2.2.15 cells) treated with saikosaponin c (SSc) secreted significantly less $\mathrm{HBeAg}$ into culture medium and had reduced HBV DNA replication [37]. Although not directly using liver cancer cells, SSa and SSd were also shown to sensitize cervical (HeLa and Siha), ovarian (SKOV3), and lung cancer cells (A549) to cisplatin-induced cell death by inducing the production of reactive oxygen species (ROS) and activation of caspases [38].

3.2. Scutellaria baicalensis. The dry root of Scutellaria baicalensis, Scutellaria radix ((SR) Hangqin, in Chinese ) is 

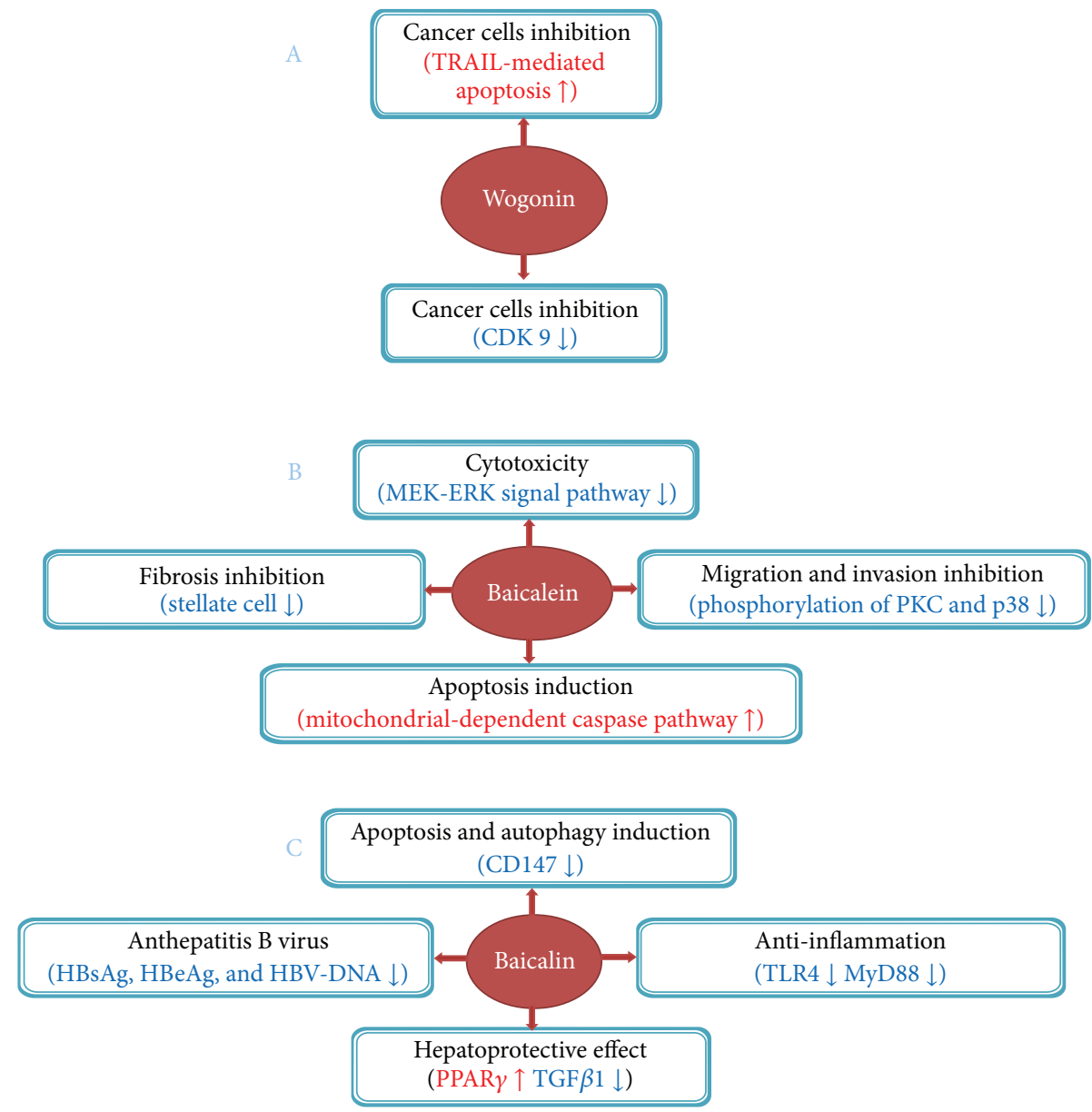

$\downarrow$ : inhibit or reduce

$\uparrow$ : activate or enhance

FIGURE 2: Suppressive effect of active components of Scutellaria radix on liver tumorigenesis and fibrosis.

another principal herb in XCHT. Accumulating evidences indicate that wogonin, baicalein, and baicalin are the principal active components in SR [39]. SR has been widely used to treat hyperlipemia, atherosclerosis, and hypertension. Recent studies with various model systems suggest that SR also possesses a potent cytostatic [40-42], anti-inflammatory [43] and antiviral capabilities [44, 45].

Antitumorigenesis ability of SR was reported by Gao et al. in human lung cancer cells (SK-MES-1, SK-LU-1, and A549) [42]. Their study showed that the absolute ethanol extracts of Scutellaria baicalensis, baicalin, baicalein, and wogonin all displayed a concentration- and time-dependent cytotoxicity to lung cancer cells while were only weakly cytotoxic to the normal human lung fibroblasts. Jung et al. later discovered that Scutellaria baicalensis is an anti-inflammatory agent because it decreases histamine release and inhibits the passive cutaneous anaphylaxis reaction in SD rats [43]. Antiviral effect of Scutellaria baicalensis was shown by Tang et al., in which it was shown to significantly inhibit the replication of HCV RNA in HCV-infected nude mice [44]. Later study revealed that the aqueous extract of Scutellaria baicalensis was also able to suppress the replication of lamivudine-resistant $\mathrm{HBV}$ mutant in human hepatoma cells by suppressing HBV core promoter activity [45].

Besides the studies performed with Scutellaria baicalensis, active components of it have also been extensively investigated (Figure 2). TNF-related apoptosis-inducing ligand (TRAIL) has been recognized as a promising anticancer agent because it kills tumor cells without damaging normal tissues $[46,47]$. However, resistance to TRAIL is frequently seen in various tumor types. Ding et al. found that wogonin and structurally related natural flavones apigenin and chrysin overcame TRAIL resistance by downregulating the level of c-FLIP (a key inhibitor of death receptor signaling) and up-regulating TRAIL receptor 2 (TRAIL-R2) expression in human T-cell leukemia virus type 1- (HTLV-1-) associated adult T leukemia/lymphoma (ATL) cells [48]. They further showed that these flavones could enhance TRAIL-mediated apoptosis in a wide variety of cancer cell types including hepatocellular carcinomas (HepG2), breast (MDA-MB-231), colon (HT-29), and pancreatic cancer cells (Capan-1) as well as melanoma cells (SK-MEL-37) [48], implicating the use 


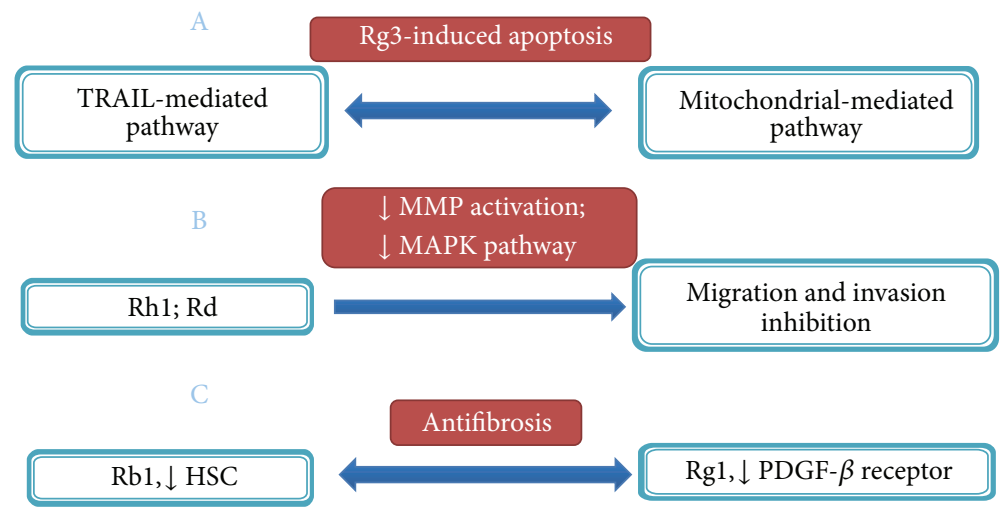

$\downarrow$ : inhibit or reduce

FIGURE 3: Antitumorigenesis effect of active components in ginseng.

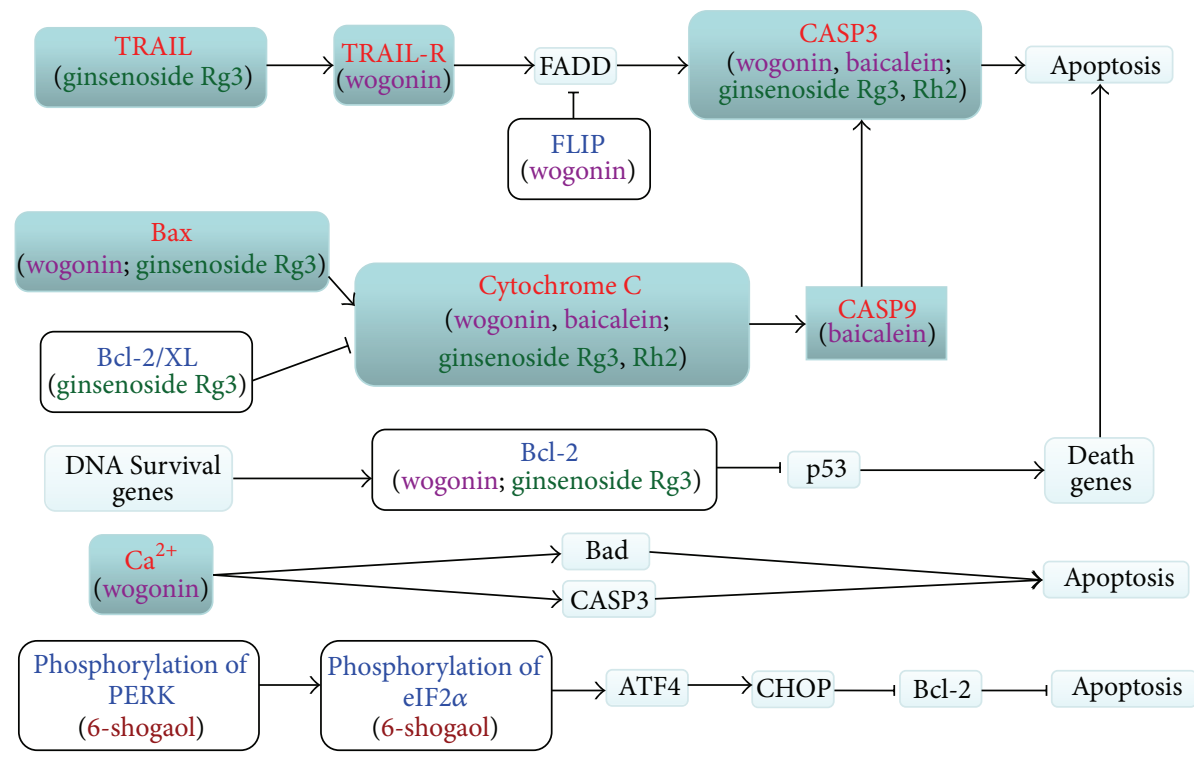

$\begin{array}{ll}\text { Wogonin, baicalein: Scutellaria baicalensis } & \text { Blue: downregulated } \\ \text { Ginsenoside Rg3, Rh2: Panax ginseng } & \longrightarrow \text { : activation } \\ \text { 6-Shogaol: Zingiber officinale } & \longrightarrow \text { : inhibition } \\ \text { Red: upregulated } & \end{array}$

FIgURE 4: Tumor cell apoptosis-related pathways targeted by active components.

of flavones as an adjuvant for TRAIL-mediated anticancer therapy. In another study, Polier et al. initially showed that wogonin and flavones are inhibitors of cyclin-dependent kinase 9 (CDK9) and can effectively block phosphorylation of the carboxy-terminal domain of RNA polymerase II at Ser2, which in turn reduces RNA synthesis and subsequent downregulation of antiapoptotic protein myeloid cell leukemia 1 (Mcl-1), leading to significant apoptosis in a variety of human cancer cells [49]. However, wogonin-induced apoptosis of human hepatocarcinoma cells was found to be accompanied with Bax increase and Bcl-2 decrease [50, 51]. Anti-HBV effect of wogonin was also found in vitro and in vivo [52], with the HBV antigen and HBV DNA level reduction.
Baicalein, a flavonoid extracted from SR, has been shown to possess potent antitumorigenesis capability toward liver cancer cells. For example, baicalein is highly cytotoxic to HCC cell lines and exerts its cytotoxicity by reducing mitochondrial transmembrane potential and subsequent cytochrome c release and caspase-3/9 activation. Disruption of MEK-ERK signaling pathway is at least partially responsible for baicalein-induced cytotoxicity $[53,54]$. When used in vivo, baicalein can significantly inhibit tumor growth of HCC xenografts [53]. In another study, baicalein was reported to block cell migration and invasion of human hepatoma cells through multiple mechanisms including the suppression of MMP-2, MMP-9, and uPA expressions, blockage of NF- $\kappa$ B 


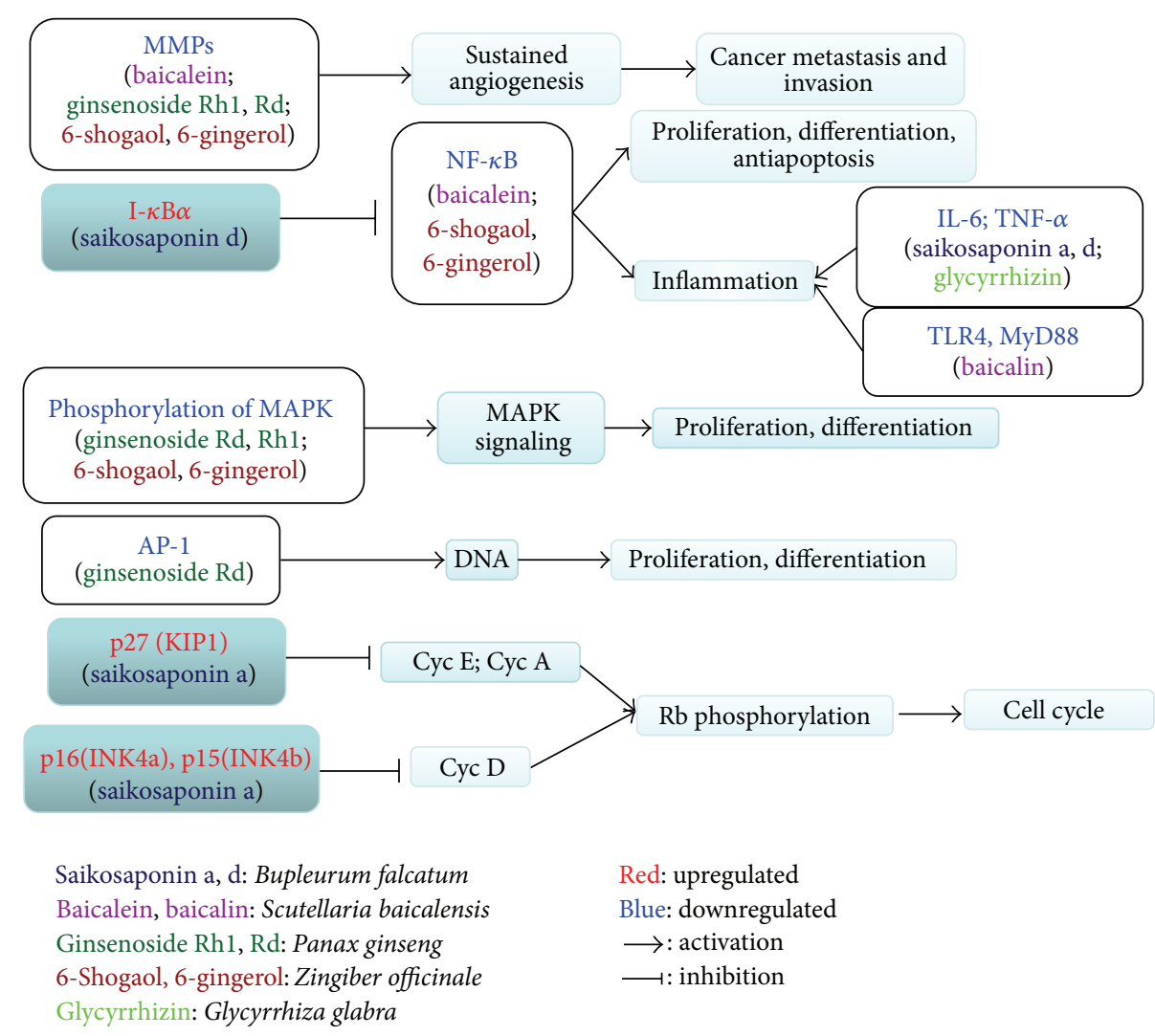

Figure 5: Tumor- and fibrosis-related pathways targeted by active components.

activation, and decreasing the phosphorylation levels of PKC $\alpha$ and p38 MAPK activities [55]. In a recent study, Sun et al. showed that baicalein dose dependently decreased AST, ALT, hyaluronic acid, laminin, and procollagen type III (PCIII) in serum as well as hydroxyproline and MMPs in liver in $\mathrm{CCl}_{4}$-induced liver fibrosis model [56]. Moreover, baicalein also alleviated inflammation, destruction of liver architecture, collagen accumulation and expression of PDGF $\beta$ receptor, thus preventing the activation of stellate cells and liver fibrosis [56].

Baicalin is also an important active component included in SR. Zhang et al. [57] found that baicalin induced apoptosis with downregulation of glycosylated immunoglobulin superfamily transmembrane protein CD147 expression in SMMC-7721 cells, and interestingly, this effect was accompanied with cell autophagy. This study firstly suggested that baicalin induced autophagy cell death in SMMC-7721 cells and revealed a new mechanism for the anticancer effects of baicalin. Qiao et al. [58] studied the antihepatic fibrosis effect of baicalin and found that transplantation with baicalintreated mesenchymal stem cells in combination with baicalin administration had the best therapeutic effect for hepatic fibrosis. This may further introduce a new therapeutic regimen for some liver diseases. Baicalin combined with oxymatrine showed better effect against HBV replication than oxymatrine in vitro, which was proved by Cheng et al. [59]. In aspects of the potential protective effect on liver injury, baicalin was also researched in many experiments [60-62].
Activation of peroxisome proliferator-activated receptor (PPAR $\gamma$ ) signaling pathway, and Toll-like receptor 4- (TLR4-) mediated inflammatory responses were involved in the protective effect.

3.3. Panax ginseng. Ginseng products are regularly consumed worldwide for the purpose of increasing vitality [63]. Recently, many studies have shown the chemopreventive or adjuvant effect of it [64]. A study involving two cases of control (905 pairs and 1987 pairs, resp.) and a cohort (4675 subjects) demonstrated the benefit of ginseng use for cancer prevention as ginseng use was found to be nonorgan-specific cancer preventive, and its effect depends on the frequency of ginseng intake [65].

In addition to ginseng's preventive effect toward cancer, evidences from experimental studies also suggest its direct role to suppress liver tumorigenesis. Wu et al. showed that ginseng lowered the rate of hepatoma development and prolonged life span on diethylnitrosamine (DEN) rat liver cancer model [66]. Kwon et al. found that oral administration of ginseng decreased the levels of AST and ALT, number of degenerative cells, and area of connective tissue in the liver of dogs during liver regeneration after partial hepatectomy [67]. Bak et al. showed that the use of ginsengs' essential oil diminished the production of ROS and restored both the activities and expression of antioxidant enzymes including superoxide dismutase (SOD), glutathione peroxidase (GPx) and catalase (CAT) in $\mathrm{H}_{2} \mathrm{O}_{2}$-treated HepG2 cells or $\mathrm{CCl}_{4}$-treated 


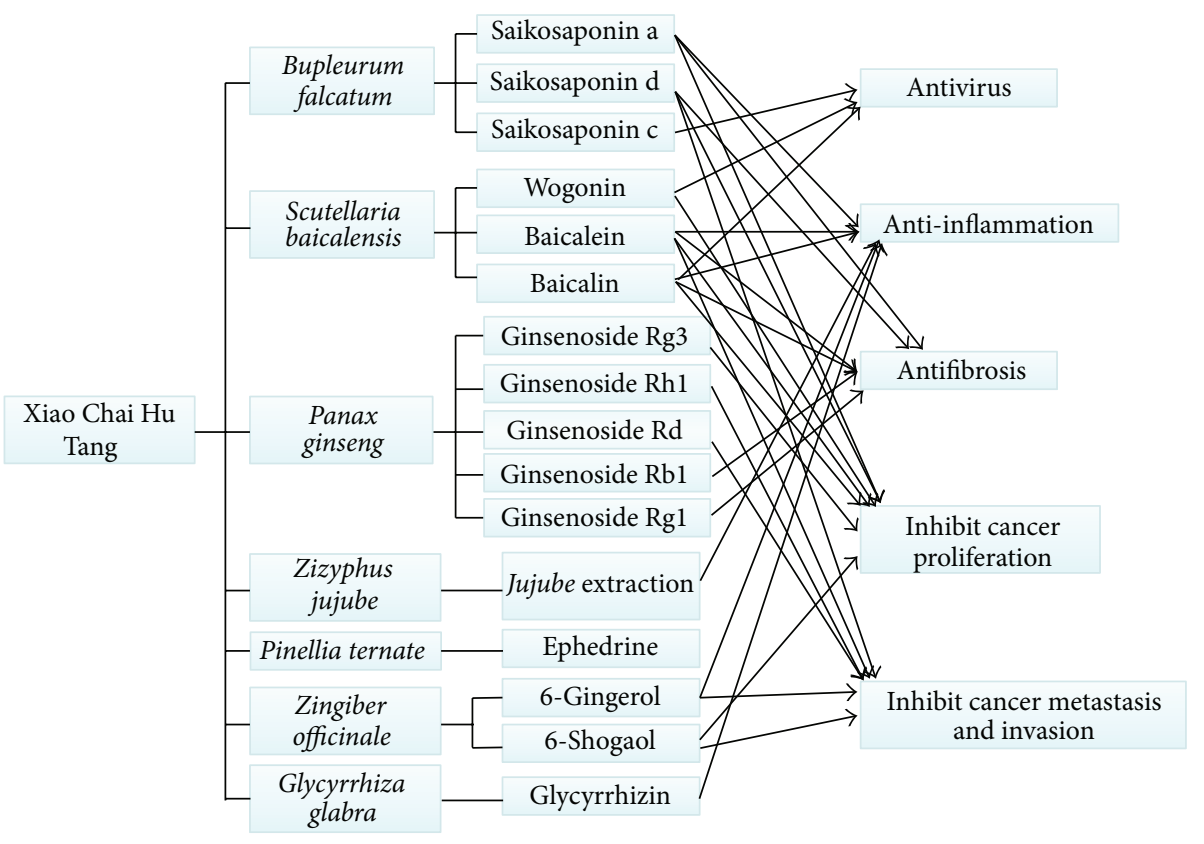

FIgURE 6: Antihepatocarcinoma effects of XCHT.

mice [68]. The effect of ginseng appears to be mediated by a simultaneous inhibition of JNK, ERK, and p38 activities and upregulated expression of antioxidant enzyme expression in the liver.

Components of ginseng have also been investigated for their inhibitory effect on liver tumorigenesis (Figure 3). Lee et al. showed that 20(S)-ginsenoside Rg3, a steroidal saponin was able to sensitize HCCs, but not normal hepatocytes to TRAIL-induced cell death [69]. Importantly, Rg3 was found to be well tolerated in animals and significantly enhance the therapeutic efficacy of TRAIL in xenograft models [69]. And other studies $[70,71]$ suggested that intrinsic apoptotic pathway may be involved in the inhibitory effect of Rg3 on hepatocellular carcinoma cell lines. To elucidate the mechanism associated with ginseng extract-induced cell death, Park et al. showed that primary ginsenosides $\mathrm{Rg} 3$ and $\mathrm{Rh} 2$ are mainly responsible for ginseng's effect and they act by directly activating mitochondrial-dependent apoptotic pathway and inducing the production of intracellular ROS [72].

Components of ginseng also exhibit their tumorsuppressing capability by blocking cell migration and invasion. Yoon et al. found that ginsenoside Rh1 inhibited HepG2 cell migration and invasion by abrogating MAPK-dependent MMP-1 expression [73]. Similar effect was also observed with ginsenoside Rd in HepG2 cells [74]. As excess production of extracellular matrix by activated hepatic stellate cells (HSCs) is the major cause of liver fibrosis, Lo et al. determined the potential protective effect of ginseng components toward liver fibrosis. They revealed that ginsenoside $\mathrm{Rb} 1$ exerted an antifibrotic effect under $\mathrm{H}_{2} \mathrm{O}_{2}$ oxidative stress by inhibiting HSC activation/proliferation [75]. Another ginsenoside, Rg1, has also been shown to prevent thioacetamide-induced hepatic fibrosis in rats by intercepting NF- $\kappa \mathrm{B}$-mediated $\operatorname{PDGF} \beta$ receptor expression [76].
3.4. Other Herbs in XCHT. Besides the three herbs that have been described above, the remaining herbs in XCHT are Zizyphus jujube, Pinellia ternate, Zingiber officinale, and Glycyrrhiza glabra and act as adjuvant herbs in this compound formula. Zizyphus jujube in XCHT is prescribed by Traditional Chinese Medicine doctors to calm mind based on its ability to invigorate the spleen and nourish the blood. Recent experimental evidences showed that it was able to attenuate chemical-induced liver injury in rats $[77,78]$. Pinellia ternate is another herb in XCHT while the mechanism study about its antihepatocarcinoma effect is rare. Although it appears to boost the efficacy of XCHT, how it does this awaits being further explored. Zingiber officinale, a species used for over thousand years, appears to display anticancer, antiinflammatory, and chemopreventive effects in both in vitro and in vivo models $[79,80]$. 6-shogaol and 6-gingerol are the two active compounds of ginger, and their effects of apoptosis induction [81], hepatocarcinoma invasion inhibition [82] and anti-hepatoxicity [83] were also studied. Licorice is the dried root of Glycyrrhiza uralensis Fisch, and both the extract $[84,85]$ and its active component glycyrrhizin $[86,87]$ were explored for their hepatoprotective capability. Though these adjuvant herbs are also essential in XCHT from the view point of TCM, modern mechanism studies about their antihepatocarcinoma effects are relatively less than Bupleurum falcatum, Scutellaria baicalensis, and Panax ginseng. So we did not summarize the antihepatocarcinoma-related effects of these adjuvant herbs as detailedly as the former three herbs here.

\section{Summary and Prospect}

Besides the summary above, experimental studies of the active components in the herbs on antihepatocarcinomarelated effects are further summarized in Tables 2, 3, 4, 
TABLE 2: Apoptosis-inducing effects of active components.

\begin{tabular}{|c|c|c|c|}
\hline Author; year & Animal or cell & Active components & Factors and pathways \\
\hline Wu and Hsu [33]; 2001 & HepG2 cells & Saikosaponin a & $\begin{array}{l}\text { PKC signaling pathway involved; } \\
\text { CDK inhibitor p- } 15^{\mathrm{INK} 4 \mathrm{a}} \text { and } \\
\text { p-16 }\end{array}$ \\
\hline Wu [34]; 2003 & HepG2 cells & Saikosaponin a & $\begin{array}{l}\text { ERK signaling pathway involved; } \\
\text { CDK inhibitor p-15 }{ }^{\mathrm{INK} 4 \mathrm{a}} \text { and } \mathrm{p}-16^{\mathrm{INK} 4 \mathrm{~b}} \\
\text { mRNA and protein } \uparrow\end{array}$ \\
\hline Wang et al. [38]; 2010 & $\begin{array}{l}\text { Cervical cancer (HeLa and Siha); } \\
\text { ovarian cancer (SKOV3); } \\
\text { non-small-cell lung cancer (A549) cell } \\
\text { lines }\end{array}$ & Saikosaponin a, d & ROS $\uparrow$; caspase pathway activation \\
\hline Ding et al. [48]; 2012 & HTLV-1-associated ATL & Wogonin & c-FLIP $\downarrow$; TRAIL-R2 expression $\uparrow$ \\
\hline Polier et al. [49]; 2011 & $\begin{array}{l}\text { The human colorectal carcinoma } \\
\text { (HCT116); } \\
\text { the human leukemic T-cell line (CEM); } \\
\text { the adult T-cell leukemic cell line (SP) }\end{array}$ & Wogonin & CDK9 $\downarrow$; antiapoptotic protein Mcl-1 $\downarrow$ \\
\hline Wang et al. [50]; 2006 & Human hepatoma cell line (SMMC-7721) & Wogonin & $\mathrm{Bax} \uparrow \mathrm{Bc} 1-2 \downarrow$ \\
\hline Lin et al. [51]; 2011 & Human osteosarcoma cell line (U-2 OS) & Wogonin & $\begin{array}{l}\operatorname{ROS} \uparrow \\
\text { intracellular } \mathrm{Ca}^{+} \uparrow \\
\text { caspase- } 3 \text { activity } \uparrow \text {; } \\
\text { Bad, Bax, cytochrome c } \uparrow \text {; } \\
\text { mitochondrial membrane potential } \downarrow\end{array}$ \\
\hline Liang et al. [53]; 2012 & $\begin{array}{l}\text { HCC cell lines; } \\
\text { mice with HCC xenografts }\end{array}$ & Baicalein & $\begin{array}{l}\text { Mitochondrial transmembrane potential } \downarrow \text {; } \\
\text { caspase-9, caspase-3 } \uparrow \text {; } \\
\text { phosphorylation of MEK1, ERK1/2, and } \\
\text { Bad } \downarrow\end{array}$ \\
\hline Kuo et al. [54]; 2009 & Human hepatoma J5 cells & Baicalein & $\begin{array}{l}\text { Mitochondrial-dependent caspase } \\
\text { activation pathway involved (mitochondrial } \\
\text { cytochrome } \mathrm{c} \text { release; activation of caspase- } 9 \\
\text { and }-3 \text {; the ratio of Bax/Bcl- } 2 \uparrow \text { ) }\end{array}$ \\
\hline Zhang et al. [57]; 2012 & HCC cell line (SMMC-7721) & Baicalin & $\begin{array}{l}\text { CD147 } \downarrow \\
\text { cell apoptosis and autophagy were induced }\end{array}$ \\
\hline Lee et al. [69]; 2012 & $\begin{array}{l}\text { HepG2, SK-Hep1, Huh-7, and Hep3B cell } \\
\text { lines; } \\
\text { mouse xenograft model }\end{array}$ & Ginsenoside Rg3 & Promoting TRAIL-induced apoptosis \\
\hline Zhang et al. [70]; 2012 & $\begin{array}{l}\text { Human hepatocellular carcinoma cell } \\
\text { lines (SMMC-7721; HepG2) }\end{array}$ & Ginsenoside Rg3 & Gene expression of caspase-3; Bax $\uparrow ; \mathrm{Bcl}-2 \downarrow$ \\
\hline Jiang et al. [71]; 2011 & $\begin{array}{l}\text { Hep1-6 and HepG2 cells; } \\
\text { liver tumor-bearing C57B16 mice }\end{array}$ & Ginsenoside Rg3 & $\begin{array}{l}\text { Mitochondrial pathway involved } \\
\text { (mitochondria membrane potential } \downarrow \text {; } \\
\text { caspase- } 3 \text { activation } \uparrow \text {; Bax } \uparrow \text { Bcl- } 2 \text { and } \\
\text { Bcl-XL } \downarrow \text { ) }\end{array}$ \\
\hline Park et al. [72]; 2012 & $\begin{array}{l}\text { Human hepatocellular carcinoma cells } \\
\text { (Hep3B) }\end{array}$ & $\begin{array}{l}\text { Ginsenoside Rg3, } \\
\text { Rh2 }\end{array}$ & $\begin{array}{l}\text { Activating the mitochondrial pathway } \\
\text { (ROS } \uparrow \text {; Bax } \uparrow \text { Bcl- } 2 \downarrow \text {; cytochrome } \mathrm{c} \uparrow \text {; } \\
\text { activation of caspase- } 3 \text { ) }\end{array}$ \\
\hline Hu et al. [81]; 2012 & $\begin{array}{l}\text { SMMC-7721, BEL-7404, HL-7702 cells; } \\
\text { SMMC-7721 xenograft-bearing mouse }\end{array}$ & 6-Shogaol & $\begin{array}{l}\text { Unfolded protein response (UPR) } \uparrow \text {; } \\
\text { PERK/eIF } 2 \alpha \text { pathway } \uparrow ; \\
\text { eIF2 } \alpha \text { phosphorylation } \downarrow ; \\
\text { caspase } 3 \uparrow\end{array}$ \\
\hline
\end{tabular}

and 5 based on their distinct cellular aspects, and some other carcinoma cell lines were also included in Tables $2-5$ to better elucidate the mechanism. What is more, to systematically organize the mechanism, we searched Kyoto
Encyclopedia of Genes and Genomes (KEGG) database (http://www.genome.jp/kegg/) to connect the factors and pathways together which were targeted by the active components, as presented in Figures 4 and 5. Though the two 
TABLE 3: Metastasis and invasion-inhibitory effects of active components.

\begin{tabular}{|c|c|c|c|}
\hline Author; year & Animal or cell & Active components & Factors and pathways \\
\hline Zhu et al. [36]; 2011 & HepG2 cells & Saikosaponin d & $\begin{array}{l}\text { Cell growth } \downarrow \text { cell migration } \downarrow ; \\
\text { AFP } \downarrow ; \text { p } 27 \text { mRNA expression } \uparrow\end{array}$ \\
\hline Chiu et al. [55]; 2011 & $\begin{array}{l}\text { human hepatoma cell } \\
\text { lines (HA22T/VGH } \\
\text { and SK-Hep1) }\end{array}$ & Baicalein & $\begin{array}{l}\text { The gelatinolytic activities of MMP-2, MMP- } 9 \text {, uPA } \downarrow \text {; } \\
\text { NF- } \kappa \text { B activation } \downarrow \text {; } \\
\text { phosphorylation of PKC } \alpha \text { and p38 proteins } \downarrow\end{array}$ \\
\hline Yoon et al. [73]; 2012 & HepG2 cells & Ginsenoside Rhl & $\begin{array}{l}\text { Inactivation of MAPKs; } \\
\text { MMP-1 gene expression } \downarrow\end{array}$ \\
\hline Yoon et al. [74]; 2012 & HepG2 cells & Ginsenoside Rd & 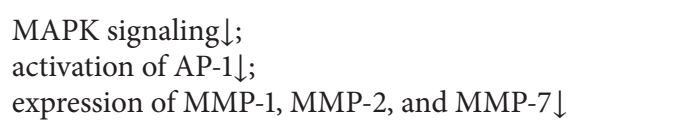 \\
\hline Weng et al. [82]; 2012 & Hep3B cells & 6-Shogaol; 6-gingerol & $\begin{array}{l}\text { MMP- } 2 \text { and MMP- } 9 \downarrow \text {; uPA } \downarrow \text {; the phosphorylation of } \\
\text { MAPK } \downarrow \text {; } \\
\text { PI3K/Akt signaling } \downarrow \text {; } \\
\text { NF- } \kappa \text { B activation } \downarrow\end{array}$ \\
\hline
\end{tabular}

TABLE 4: Inflammation and fibrosis inhibitory effects of active components.

\begin{tabular}{|c|c|c|c|}
\hline Author; year & Animal or cell & Active components & Factors and pathways \\
\hline Wu et al. [31]; 2010 & $\begin{array}{l}\mathrm{CCl}_{4} \text {-induced liver } \\
\text { inflammation and } \\
\text { fibrosis rats }\end{array}$ & Saikosaponin a & $\begin{array}{l}\text { Proinflammatory cytokines TNF- } \alpha \text {, IL- } 1 \beta \text {, IL- } 6 \downarrow \text {; } \\
\text { anti-inflammatory cytokine IL-10个; } \\
\text { TGF- } \beta 1 \text { and hydroxyproline } \downarrow \text {; NF- } \kappa \mathrm{B} \downarrow\end{array}$ \\
\hline Dang et al. [32]; 2007 & Liver fibrotic rats & Saikosaponin d & $\begin{array}{l}\text { TNF- } \alpha \text {, IL- } 6 \text { and NF- } \kappa \text { Bp } 65 \text { expression } \downarrow \\
\text { I- } \kappa \text { B } \alpha \text { activity } \uparrow\end{array}$ \\
\hline Sun et al. [56]; 2010 & $\begin{array}{l}\mathrm{CCl}_{4} \text {-induced liver } \\
\text { fibrosis rats }\end{array}$ & Baicalein & $\begin{array}{l}\text { AST, ALT, hyaluronic acid, laminin, and PDGF- } \beta \\
\text { receptor } \downarrow \text {; } \\
\text { hydroxyproline, MMPs } \downarrow\end{array}$ \\
\hline Qiao et al. [60]; 2011 & $\begin{array}{l}\mathrm{CCl}_{4} \text {-induced liver } \\
\text { injury rats }\end{array}$ & Baicalin & $\operatorname{PPAR} \gamma \uparrow ; \mathrm{TGF} \beta 1 \downarrow$ \\
\hline Kim and Lee [62]; 2012 & $\begin{array}{l}\text { Ischemia/reperfusion } \\
\text { injured rats with } \\
\text { alcoholic fatty liver }\end{array}$ & Baicalin & $\begin{array}{l}\text { Toll-like receptor } 4 \text { (TLR4) } \downarrow \text {; } \\
\text { myeloid differentiation primary response protein My88 } \downarrow\end{array}$ \\
\hline Lo et al. [75]; 2011 & HSCs & Ginsenoside Rbl & $\begin{array}{l}\text { HSCs activation and proliferation } \downarrow \text {; } \\
\text { expression of collagen, TGF- } \beta 1 \text {, MMP- } 2 \text {, and TIMP- } 1 \downarrow\end{array}$ \\
\hline Geng et al. [76]; 2010 & $\begin{array}{l}\text { Thioacetamide-treated } \\
\text { rats; HSCs }\end{array}$ & Ginsenoside Rg1 & $\begin{array}{l}\text { AST, ALT, hydroxyproline } \downarrow \text {; } \\
\text { HSCs } \downarrow \text {; PDGF- } \beta \text { receptor expression } \downarrow\end{array}$ \\
\hline Sabina et al. [83]; 2011 & $\begin{array}{l}\text { Acetaminophen-treated } \\
\text { mice }\end{array}$ & 6-gingerol & $\begin{array}{l}\text { The hepatic marker enzymes (AST, ALT, and ALP) and } \\
\text { total bilirubin in serum } \downarrow \text {; } \\
\text { hepatic malondialdehyde formation } \downarrow \text {; } \\
\text { liver antioxidant status } \uparrow\end{array}$ \\
\hline Gumpricht et al. [86]; 2005 & $\begin{array}{l}\text { Rat hepatocytes exposed } \\
\text { to GCDC }\end{array}$ & $\begin{array}{l}\text { Glycyrrhizin; } \\
\text { 18-beta-glycyrrhetinic } \\
\text { acid }\end{array}$ & $\begin{array}{l}\text { Glycyrrhizin-enhanced GCDC induced cell apoptosis; } \\
\text { 18-beta-glycyrrhetinic acid reduced cell necrosis and } \\
\text { protected against GCDC-induced cell apoptosis }\end{array}$ \\
\hline Lee et al. [87]; 2007 & $\begin{array}{l}\mathrm{CCl}_{4} \text {-induced liver } \\
\text { injury rats }\end{array}$ & Glycyrrhizin & 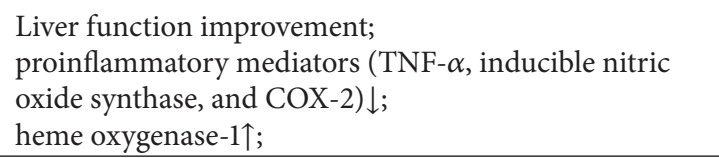 \\
\hline
\end{tabular}

TABLE 5: Antiviral effect of active components.

\begin{tabular}{llcc}
\hline Author; year & Animal or cell & Active components & Factors and pathways \\
\hline Chiang et al. [37]; 2003 & HBV-transfected human hepatoma cells & Saikosaponin c & HBeAg $\downarrow$ HBV DNA $\downarrow$ \\
Guo et al. [52]; 2007 & HepG2.2.15; HBV-infected ducks; & Wogonin & HBsAg and HBeAg $\downarrow ;$ HBV DNA $\downarrow$ \\
Cheng et al. [59]; 2006 & HepG-transgenic mice & Baicalin & HBsAg and HBeAg $\downarrow ;$ HBV DNA $\downarrow$ \\
\hline
\end{tabular}


figures cannot present all the targets summarized in our paper, they still could illustrate the mechanism from a more systematical aspect. On the basis of Figures 1 to 5, we depicted Figure 6 to better display the antihepatocarcinoma effects at three different levels of formula, herbs, and components. From them, it is apparent that components of XCHT possess a broad spectrum of activities ranging from antitumor, antiinflammation to fibrosis-protective effects. Some of the components directly target on tumor growth, metastasis, and invasion, while others act on inflammation and fibrosis related pathways or antiviral process to prevent further virus-facilitated tumorigenesis. Particularly, many of these components share analogous factors and pathways.

Besides tumor growth, metastasis and invasion, angiogenesis is also an essential pathological component of cancer. Antiangiogenic therapy is considered to limit tumor progression [88]. Research about the anti-angiogenic effect on hepatocarcinoma of XCHT has not been seen, while some reseachers have studied the effect of herbs and active compounds in it on the angiogenic action [89-91]. Interestingly, different compounds in ginseng (ginsenoside Rg3 and Rg1) possessed contrary angiogenic action (antiangiogenic and angiogenic effects) $[89,90]$. What is more, as we summarized in our review, components of XCHT may affect various biochemical pathways, many of which are related to angiogenesis [92]. So it is also worthy to deeply study XCHT's effect on the angiogenic action for tumor treatment.

Our overview is based on a perspective of "separation study," that is, arranging from the entire formula to each herb and their active components. This method may comprehensively utilize and deeply excavate the existing researches. It is difficult to directly elucidate a complex formula, while it will be easier when we separately study the constituents in it. Currently, to unequivocally interpret the antihepatocarcinoma effect of XCHT and the active ingredients contained in it is still difficult. The underlying reasons are severalfold. The first is that the knowledge on how each component works is still not sufficient and their respective targets are still needed to be identified. The second is how these components work in concert to achieve therapeutic effect is not understood. As the philosophy of Traditional Chinese Medicine, compound herbal formulas are used to treat disease by regulating human body globally, targeting multiple pathways and targets. This characteristic may be better coincident with cancer which may be induced by multiple factors. Tumor growth, metastasis, and invasion are the final features that we notice, but the underlying mechanism may be related with many factors. The method of "separation study" should be combined with bioinformatics, meaning that we may use bioinformatics to integrate these separated studies. So more innovative researches and novel strategies will have to be employed to fully understand the mechanisms responsible for XCHT's therapeutic effects.

\section{Abbreviations}

ATL: Adult T-cell leukemia/lymphoma

ALP: Alkaline phosphatase

AFP: Alpha-fetoprotein
AP-1: $\quad$ Activator protein-1

ATF4: Cyclic AMP-dependent transcription factor

c-FLIP: Cellular FLICE inhibitory protein (CASP8 and FADD-like apoptosis regulator)

CASP: $\quad$ Caspase

CycD: $\quad$ Cyclin D

CDK9: $\quad$ Cyclin-dependent kinase 9

COX-2: Cyclooxygenase 2

$\mathrm{C} / \mathrm{EBP} \beta: \quad \mathrm{CCAAT} /$ enhancer-binding protein $\beta$

CD147: Glycosylated immunoglobulin superfamily transmembrane protein

CHOP: $\quad$ C/EBP homologous protein

DEN: Diethylnitrosamine

ERK: $\quad$ Extracellular signal-regulated kinase

eIF2 $\alpha$ : Translation initiation factor

FADD: $\quad$ FAS-associated death domain protein

GCDC: Glycochenodeoxycholic acid

HTLV-1: Human T-cell leukemia virus type1

HSCs: $\quad$ Hepatic stellate cells

HBsAg: Hepatitis B surface antigen

HBeAg: Hepatitis B e antigen

I- $\kappa \mathrm{B} \alpha: \quad$ NF-kappa-B inhibitor alpha

Mcl-1: $\quad$ Myeloid cell leukemia-1

MMP: $\quad$ Matrix metalloproteinase

MAPK: Mitogen-activated protein kinase

My88: $\quad$ Myeloid differentiation primary response protein

PKC: $\quad$ Protein kinase C

PDGF: $\quad$ Platelet derived growth factor

PERK: $\quad$ PKR-like endoplasmic reticulum associated kinase (eukaryotic translation initiation factor kinase)

PPAR $\gamma: \quad$ Peroxisome proliferator-activated receptor $\gamma$ ROS: $\quad$ Reactive oxygen species

Rb: Retinoblastoma-associated protein

TRAIL-R2: TNF-related apoptosis-inducing ligand receptor 2

TIMP: $\quad$ Tissue inhibitor of metalloproteinase

TGF $\beta 1$ : $\quad$ Tumor growth factor $\beta 1$

TLR4: $\quad$ Toll-like receptor 4

uPA: Urokinase plasminogen activator.

\section{Authors' Contribution}

Ningning Zheng, Jianye Dai, and Huijuan Cao have contributed equally to this work and should be considered as cofirst authors.

\section{Acknowledgments}

This paper was supported by Shanghai Interdisciplinary Cultivation Platform of Outstanding and Innovative Postgraduates and Shanghai "085" Science and Technology Innovation Supporting Project for Top-Grade Discipline Construction.

\section{References}

[1] http://www.cancer.org/cancer/livercancer/overviewguide/livercancer-overview-key-statistics. 
[2] H. B. El-Serag, "Epidemiology of viral hepatitis and hepatocellular carcinoma," Gastroenterology, vol. 142, no. 6, pp. 12641273, 2012.

[3] E. A. Akriviadis, J. M. Llovet, S. C. Efremidis et al., "Hepatocellular carcinoma," British Journal of Surgery, vol. 85, no. 10, pp. 1319-1331, 1998.

[4] I. Hyodo, N. Amano, K. Eguchi et al., "Nationwide survey on complementary and alternative medicine in cancer patients in Japan," Journal of Clinical Oncology, vol. 23, no. 12, pp. 26452654, 2005.

[5] X. Q. Li and C. Q. Ling, "Chinese herbal medicine for side effects of transarterial chemoembolization in liver cancer patients: a systematic review and meta-analysis," Zhong Xi Yi Jie He Xue Bao, vol. 10, no. 12, pp. 1341-1362, 2012.

[6] J. L. McQuade, Z. Meng, Z. Chen et al., "Utilization of and attitudes towards traditional Chinese medicine therapies in a Chinese cancer hospital: a survey of patients and physicians," Evidence-Based Complementary and Alternative Medicine, vol. 2012, Article ID 504507, 11 pages, 2012.

[7] W.-J. Ruan, M.-D. Lai, and J.-G. Zhou, "Anticancer effects of Chinese herbal medicine, science or myth?" Journal of Zhejiang University. Science. B, vol. 7, no. 12, pp. 1006-1014, 2006.

[8] C. Hirayama, M. Okumura, K. Tanikawa, M. Yano, M. Mizuta, and N. Ogawa, "A multicenter randomized controlled clinical trial of Shosaiko-to in chronic active hepatitis," Gastroenterologia Japonica, vol. 24, no. 6, pp. 715-719, 1989.

[9] H. Oka, A. Yamamoto, T. Kuroki et al., "Prospective study of chemoprevention of hepatocellular carcinoma with Shosaikoto (TJ-9)," Cancer, vol. 76, no. 5, pp. 743-749, 1995.

[10] X.-K. Qin, P. Li, M. Han, and J.-P. Liu, "Xiaochaihu Tang for treatment of chronic hepatitis B: a systematic review of randomized trials," Journal of Chinese Integrative Medicine, vol. 8, no. 4, pp. 312-320, 2010.

[11] G. Deng, R. C. Kurtz, A. Vickers et al., "A single arm phase II study of a Far-Eastern traditional herbal formulation (shosai-ko-to or xiao-chai-hu-tang) in chronic hepatitis C patients," Journal of Ethnopharmacology, vol. 136, no. 1, pp. 83-87, 2011.

[12] I. Shimizu, "Sho-saiko-to: Japanese herbal medicine for protection against hepatic fibrosis and carcinoma," Journal of Gastroenterology and Hepatology, vol. 15, supplement, pp. D84D90, 2000.

[13] J.-K. Lee, J.-H. Kim, and H. K. Shin, "Therapeutic effects of the oriental herbal medicine Sho-saiko-to on liver cirrhosis and carcinoma," Hepatology Research, vol. 41, no. 9, pp. 825-837, 2011.

[14] Q. L. Bo and W. W. Du, "Effect observation of fifty chronic hepatitis B patients under the treatment of interferon combined with xiaochaihu tang," Shandong Medical Journal, vol. 46, no. 8, pp. 82-83, 2006 (Chinese).

[15] Z. Li, H. H. Liao, M. J. Wu, and Z. H. Lin, "Study on the combination treatment of $\gamma$-interferon and xiaochaihu tang on liver fibrosis," Chinese Journal of Integrated Traditional and Western Medicine on Liver Diseases, vol. 11, supplement, p. 95, 2001 (Chinese).

[16] W. H. Sun, M. Q. Song, and Z. J. Liu, "Study on the combination treatment of xiaochaihu tang and oxymatrine on hepatitis and hepato-fibrosis," Chinese Journal of Integrated Traditional and Western Medicine on Liver Diseases, vol. 13, no. 1, pp. 41-42, 2003 (Chinese).
[17] Q. Q. Wu, "Clinical observation on the effect of xiaochaihu tang on chronic hepatitis B with cirrhosis patients," Journal of Zhejiang College of Traditional Chinese Medicine, vol. 33, no. 4, pp. 517-518, 2009 (Chinese).

[18] H. Yano, A. Mizoguchi, K. Fukuda et al., "The herbal medicine sho-saiko-to inhibits proliferation of cancer cell lines by inducing apoptosis and arrest at the G0/G1 phase," Cancer Research, vol. 54, no. 2, pp. 448-454, 1994.

[19] T. Makino, R. Tsubouchi, K. Murakami, M. Haneda, and M. Yoshino, "Generation of reactive oxygen species and induction of apoptosis of HL60 cells by ingredients of traditional herbal medicine, Sho-saiko-to," Basic and Clinical Pharmacology and Toxicology, vol. 98, no. 4, pp. 401-405, 2006.

[20] K. Zhu, I. Fukasawa, M. Furuno et al., "Inhibitory effects of herbal drugs on the growth of human ovarian cancer cell lines through the induction of apoptosis," Gynecologic Oncology, vol. 97, no. 2, pp. 405-409, 2005.

[21] J. Li, M. Xie, and Y. Gan, "Effect of Xiaochaihu decoction and different herbal formulation of component on inhibiting H22 liver cancer in mice and enhancing immune function," Zhongguo Zhongyao Zazhi, vol. 33, no. 9, pp. 1039-1044, 2008 (Chinese).

[22] J.-S. Chang, K.-C. Wang, H.-W. Liu, M.-C. Chen, L.-C. Chiang, and C.-C. Lin, "Sho-saiko-to (Xiao-Chai-Hu-Tang) and crude saikosaponins inhibit Hepatitis B virus in a stable HBVproducing cell line," American Journal of Chinese Medicine, vol. 35, no. 2, pp. 341-351, 2007.

[23] P.-W. Cheng, L.-T. Ng, and C.-C. Lin, "Xiao Chai Hu Tang inhibits CVB1 virus infection of CCFS-1 cells through the induction of type I interferon expression," International Immunopharmacology, vol. 6, no. 6, pp. 1003-1012, 2006.

[24] A. Cucchetti, M. Cescon, F. Trevisani, and A. D. Pinna, "Current concepts in hepatic resection for hepatocellular carcinoma in cirrhotic patients," World Journal of Gastroenterology, vol. 18, no. 44, pp. 6398-6408, 2012.

[25] M. Kusunose, B. Qiu, T. Cui et al., "Effect of Sho-saiko-to extract on hepatic inflammation and fibrosis in dimethylnitrosamine induced liver injury rats," Biological and Pharmaceutical Bulletin, vol. 25, no. 11, pp. 1417-1421, 2002.

[26] M.-H. Chen, J.-C. Chen, C.-C. Tsai et al., "The role of TGF- $\beta 1$ and cytokines in the modulation of liver fibrosis by Sho-saiko-to in rat's bile duct ligated model," Journal of Ethnopharmacology, vol. 97, no. 1, pp. 7-13, 2005.

[27] B. S. Dun, Fang Ji Xue, Xi'an Jiaotong University Press, Xian, China, 2nd edition, 2011.

[28] B. Lee, I. Shim, H. Lee, and D.-H. Hahm, "Effect of Bupleurum falcatum on the stress-induced impairment of spatial working memory in rats," Biological and Pharmaceutical Bulletin, vol. 32, no. 8, pp. 1392-1398, 2009.

[29] M.-H. Yen, T.-C. Weng, S.-Y. Liu, C.-Y. Chai, and C.-C. Lin, "The hepatoprotective effect of Bupleurum kaoi, an endemic plant to Taiwan, against dimethylnitrosamine-induced hepatic fibrosis in rats," Biological and Pharmaceutical Bulletin, vol. 28, no. 3, pp. 442-448, 2005.

[30] S. M. Kim, S. C. Kim, I. K. Chung, W. H. Cheon, and S. K. $\mathrm{Ku}$, "Antioxidant and protective effects of Bupleurum falcatum on the L-thyroxine-induced hyperthyroidism in rats," EvidenceBased Complementary and Alternative Medicine, vol. 2012, Article ID 578497, 12 pages, 2012. 
[31] S.-J. Wu, K.-W. Tam, Y.-H. Tsai, C.-C. Chang, and J. C.-J. Chao, "Curcumin and saikosaponin a inhibit chemical-induced liver inflammation and fibrosis in rats," American Journal of Chinese Medicine, vol. 38, no. 1, pp. 99-111, 2010.

[32] S.-S. Dang, B.-F. Wang, Y.-A. Cheng, P. Song, Z.-G. Liu, and Z.-F. Li, "Inhibitory effects of saikosaponin-d on $\mathrm{CCl}_{4}$-induced hepatic fibrogenesis in rats," World Journal of Gastroenterology, vol. 13, no. 4, pp. 557-563, 2007.

[33] W.-S. Wu and H.-Y. Hsu, "Involvement of p-15 $5^{\text {INK4b }}$ and p- $16^{\text {INK4a }}$ gene expression in saikosaponin a and TPA-induced growth inhibition of HepG2 cells," Biochemical and Biophysical Research Communications, vol. 285, no. 2, pp. 183-187, 2001.

[34] W.-S. Wu, "ERK signaling pathway is involved in $\mathrm{p} 15^{\mathrm{INK} 4 \mathrm{~b}} / \mathrm{p} 16^{\mathrm{INK} 4 \mathrm{a}}$ expression and HepG2 growth inhibition triggered by TPA and Saikosaponin a," Oncogene, vol. 22, no. 7, pp. 955-963, 2003.

[35] X.-L. Lu, S.-X. He, M.-D. Ren, Y.-L. Wang, Y.-X. Zhang, and E.-Q. Liu, "Chemopreventive effect of saikosaponin-d on diethylinitrosamine-induced hepatocarcinogenesis: involvement of CCAAT/enhancer binding protein $\beta$ and cyclooxygenase-2," Molecular Medicine Reports, vol. 5, no. 3, pp. 637-644, 2012.

[36] B. H. Zhu, R. Pu, G. P. Zhang, M. Y. Li, L. T. Wang, and J. K. Yuan, "Effect of Saikosaponins-d on reversing malignant phenotype of HepG2 cells in vitro," Zhonghua Gan Zang Bing Za Zhi, vol. 19, no. 10, pp. 764-767, 2011 (Chinese).

[37] L.-C. Chiang, L. T. Ng, L.-T. Liu, D.-E. Shieh, and C.-C. Lin, "Cytotoxicity and anti-hepatitis B virus activities of saikosaponins from Bupleurum species," Planta Medica, vol. 69, no. 8, pp. 705-709, 2003.

[38] Q. Wang, X.-L. Zheng, L. Yang et al., "Reactive oxygen speciesmediated apoptosis contributes to chemosensitization effect of saikosaponins on cisplatin-induced cytotoxicity in cancer cells," Journal of Experimental and Clinical Cancer Research, vol. 29, no. 1, article 159, 2010.

[39] M. Li-Weber, "New therapeutic aspects of flavones: the anticancer properties of Scutellaria and its main active constituents Wogonin, Baicalein and Baicalin," Cancer Treatment Reviews, vol. 35, no. 1, pp. 57-68, 2009.

[40] S. Ikemoto, K. Sugimura, N. Yoshida et al., "Antitumor effects of Scutellariae radix and its components baicalein, baicalin, and wogonin on bladder cancer cell lines," Urology, vol. 55, no. 6, pp. 951-955, 2000.

[41] D. Y. Zhang, J. Wu, F. Ye et al., "Inhibition of cancer cell proliferation and prostaglandin E2 synthesis by Scutellaria baicalensis," Cancer Research, vol. 63, no. 14, pp. 4037-4043, 2003.

[42] J. Gao, W. A. Morgan, A. Sanchez-Medina, and O. Corcoran, "The ethanol extract of Scutellaria baicalensis and the active compounds induce cell cycle arrest and apoptosis including upregulation of p53 and Bax in human lung cancer cells," Toxicology and Applied Pharmacology, vol. 254, no. 3, pp. 221$228,2011$.

[43] H.-S. Jung, M. H. Kim, N.-G. Gwak et al., "Antiallergic effects of Scutellaria baicalensis on inflammation in vivo and in vitro," Journal of Ethnopharmacology, vol. 141, no. 1, pp. 345-349, 2012.

[44] Z.-M. Tang, M. Peng, and C.-J. Zhan, "Screening 20 Chinese herbs often used for clearing heat and dissipating toxin with nude mice model of hepatitis C viral infection," Zhongguo
Zhong Xi Yi Jie He Za Zhi, vol. 23, no. 6, pp. 447-448, 2003 (Chinese).

[45] Y. P. Tseng, Y. C. Wu, Y. L. Leu, S. F. Yeh, and C. K. Chou, "Scutellariae radix suppresses hepatitis B virus production in human hepatoma cells," Frontiers in Bioscience, vol. 2, pp. 1538$1547,2010$.

[46] S. R. Wiley, K. Schooley, P. J. Smolak et al., "Identification and characterization of a new member of the TNF family that induces apoptosis," Immunity, vol. 3, no. 6, pp. 673-682, 1995.

[47] B. R. James and T. S. Griffith, "Activation of systemic antitumor immunity via TRAIL-induced apoptosis," Oncoimmunology, vol. 1, no. 7, pp. 1178-1180, 2012.

[48] J. Ding, G. Polier, R. Köhler, M. Giaisi, P. H. Krammer, and M. Li-Weber, "Wogonin and related natural flavones overcome tumor necrosis factor-related apoptosis-inducing ligand (TRAIL) protein resistance of tumors by down-regulation of c-FLIP protein and up-regulation of TRAIL receptor 2 expression," The Journal of Biological Chemistry, vol. 287, no. 1, pp. 641649, 2012.

[49] G. Polier, J. Ding, B. V. Konkimalla et al., "Wogonin and related natural flavones are inhibitors of CDK9 that induce apoptosis in cancer cells by transcriptional suppression of Mcl-1," Cell Death \& Disease, vol. 2, no. 7, article e182, 2011.

[50] W. Wang, Q. Guo, Q. You et al., "Involvement of bax/bcl-2 in wogonin-induced apoptosis of human hepatoma cell line SMMC-7721," Anti-Cancer Drugs, vol. 17, no. 7, pp. 797-805, 2006.

[51] C.-C. Lin, C.-L. Kuo, M.-H. Lee et al., "Wogonin triggers apoptosis in human osteosarcoma U-2 OS cells through the endoplasmic reticulum stress, mitochondrial dysfunction and caspase-3-dependent signaling pathways," International Journal of Oncology, vol. 39, no. 1, pp. 217-224, 2011.

[52] Q. Guo, L. Zhao, Q. You et al., "Anti-hepatitis B virus activity of wogonin in vitro and in vivo," Antiviral Research, vol. 74, no. 1, pp. 16-24, 2007.

[53] R. R. Liang, S. Zhang, J. A. Qi et al., "Preferential inhibition of hepatocellular carcinoma by the flavonoid Baicalein through blocking MEK-ERK signaling," International Journal of Oncology, vol. 41, no. 3, pp. 969-978, 2012.

[54] H.-M. Kuo, H.-C. Tsai, Y.-L. Lin et al., "Mitochondrialdependent caspase activation pathway is involved in baicaleininduced apoptosis in human hepatoma J5 cells," International Journal of Oncology, vol. 35, no. 4, pp. 717-724, 2009.

[55] Y.-W. Chiu, T.-H. Lin, W.-S. Huang et al., "Baicalein inhibits the migration and invasive properties of human hepatoma cells," Toxicology and Applied Pharmacology, vol. 255, no. 3, pp. 316326, 2011.

[56] H. Sun, Q.-M. Che, X. Zhao, and X.-P. Pu, "Antifibrotic effects of chronic baicalein administration in a $\mathrm{CCl}_{4}$ liver fibrosis model in rats," European Journal of Pharmacology, vol. 631, no. 1-3, pp. 53-60, 2010.

[57] X. Zhang, X. Tang, H. Liu, L. Li, Q. Hou, and J. Gao, "Autophagy induced by baicalin involves downregulation of CD147 in SMMC-7721 cells in vitro," Oncology Reports, vol. 27, no. 4, pp. 1128-1134, 2012.

[58] H. Qiao, Y. Tong, H. Han et al., "A novel therapeutic regimen for hepatic fibrosis using the combination of mesenchymal stem cells and baicalin," Pharmazie, vol. 66, no. 1, pp. 37-43, 2011. 
[59] Y. Cheng, J. Ping, H.-D. Xu, H.-J. Fu, and Z.-H. Zhou, "Synergistic effect of a noval oxymatrine-baicalin combination against hepatitis $\mathrm{B}$ virus replication, $\alpha$ smooth muscle actin expression and type I collagen synthesis in vitro," World Journal of Gastroenterology, vol. 12, no. 32, pp. 5153-5159, 2006.

[60] H. Qiao, H. Han, D. Hong, Z. Ren, Y. Chen, and C. Zhou, "Protective effects of baicalin on carbon tetrachloride induced liver injury by activating PPAR $\gamma$ and inhibiting TGF $\beta 1$," Pharmaceutical Biology, vol. 49, no. 1, pp. 38-45, 2011.

[61] S.-W. Park, C.-H. Lee, Y. S. Kim et al., "Protective effect of baicalin against carbon tetrachloride-induced acute hepatic injury in mice," Journal of Pharmacological Sciences, vol. 106, no. 1, pp. 136-143, 2008.

[62] S.-J. Kim and S.-M. Lee, "Effect of baicalin on toll-like receptor 4-mediated ischemia/reperfusion inflammatory responses in alcoholic fatty liver condition," Toxicology and Applied Pharmacology, vol. 258, no. 1, pp. 43-50, 2012.

[63] L. Jia, Y. Zhao, and X.-J. Liang, "Current evaluation of the millennium phytomedicine-ginseng (II): collected chemical entities, modern pharmacology, and clinical applications emanated from traditional chinese medicine," Current Medicinal Chemistry, vol. 16, no. 22, pp. 2924-2942, 2009.

[64] S. Helms, "Cancer prevention and therapeutics: Panax ginseng," Alternative Medicine Review, vol. 9, no. 3, pp. 259-274, 2004.

[65] T. K. Yun, S. Y. Choi, and H. Y. Yun, "Epidemiological study on cancer prevention by ginseng: are all kinds of cancers preventable by ginseng?" Journal of Korean Medical Science, vol. 16, supplement, pp. S19-S27, 2001.

[66] X. G. Wu, D. H. Zhu, and X. Li, "Anticarcinogenic effect of red ginseng on the development of liver cancer induced by diethylnitrosamine in rats," Journal of Korean Medical Science, vol. 16, supplement, pp. S61-S65, 2001.

[67] Y.-S. Kwon, K.-H. Jang, and I.-H. Jang, "The effects of Korean red ginseng (ginseng radix rubra) on liver regeneration after partial hepatectomy in dogs," Journal of Veterinary Science, vol. 4, no. 1, pp. 83-92, 2003.

[68] M.-J. Bak, M. Jun, and W.-S. Jeong, "Antioxidant and hepatoprotective effects of the red ginseng essential oil in $\mathrm{H}_{2} \mathrm{O}_{2}$-treated HepG2 cells and $\mathrm{CCl}_{4}$-treated mice," International Journal of Molecular Sciences, vol. 13, no. 2, pp. 2314-2330, 2012.

[69] J. Y. Lee, K. H. Jung, M. J. Morgan et al., "Sensitization of TRAIL-induced cell death by 20S-Ginsenoside $\mathrm{Rg} 3$ via CHOP-mediated DR5 upregulation in human hepatocellular carcinoma cells," Molecular Cancer Therapeutics, 2012.

[70] C. Zhang, L. Liu, Y. Yu, B. Chen, C. Tang, and X. Li, "Antitumor effects of ginsenoside $\mathrm{Rg} 3$ on human hepatocellular carcinoma cells," Molecular Medicine Reports, vol. 5, no. 5, pp. 1295-1298, 2012.

[71] J.-W. Jiang, X.-M. Chen, X.-H. Chen, and S.-S. Zheng, "Ginsenoside Rg3 inhibit hepatocellular carcinoma growth via intrinsic apoptotic pathway," World Journal of Gastroenterology, vol. 17, no. 31, pp. 3605-3613, 2011.

[72] H. M. Park, S. J. Kim, J. S. Kim, and H. S. Kang, "Reactive oxygen species mediated ginsenoside Rg3-and Rh2-induced apoptosis in hepatoma cells through mitochondrial signaling pathways," Food and Chemical Toxicology, vol. 50, no. 8, pp. 2736-2741, 2012.

[73] J.-H. Yoon, Y.-J. Choi, and S.-G. Lee, "Ginsenoside Rh1 suppresses matrix metalloproteinase-1 expression through inhibition of activator protein- 1 and mitogen-activated protein kinase signaling pathway in human hepatocellular carcinoma cells," European Journal of Pharmacology, vol. 679, no. 1-3, pp. 24-33, 2012.

[74] J.-H. Yoon, Y.-J. Choi, S.-W. Cha, and S.-G. Lee, "Anti-metastatic effects of ginsenoside Rd via inactivation of MAPK signaling and induction of focal adhesion formation," Phytomedicine, vol. 19, no. 3-4, pp. 284-292, 2012.

[75] Y.-T. Lo, Y.-H. Tsai, S.-J. Wu, J.-R. Chen, and J. C.-J. Chao, "Ginsenoside Rb1 inhibits cell activation and liver fibrosis in rat hepatic stellate cells," Journal of Medicinal Food, vol. 14, no. 10, pp. 1135-1143, 2011.

[76] J. Geng, W. Peng, Y. Huang, H. Fan, and S. Li, "GinsenosideRg1 from Panax notoginseng prevents hepatic fibrosis induced by thioacetamide in rats," European Journal of Pharmacology, vol. 634, no. 1-3, pp. 162-169, 2010.

[77] C. F. Chen, J. F. Lee, D. Wang, C. Y. Shen, K. L. Shen, and M. H. Lin, "Water extract of Zizyphus Jujube attenuates ischemia/reperfusion-induced liver injury in rats (PP106)," Transplantation Proceedings, vol. 42, no. 3, pp. 741-743, 2010.

[78] X. Shen, Y. Tang, R. Yang, L. Yu, T. Fang, and J.-A. Duan, "The protective effect of Zizyphus jujube fruit on carbon tetrachloride-induced hepatic injury in mice by anti-oxidative activities," Journal of Ethnopharmacology, vol. 122, no. 3, pp. 555-560, 2009.

[79] S. H. M. Habib, S. Makpol, N. A. A. Hamid, S. Das, W. Z. W. Ngah, and Y. A. M. Yusof, "Ginger extract (Zingiber officinale) has anti-cancer and anti-inflammatory effects on ethionineinduced hepatoma rats," Clinics, vol. 63, no. 6, pp. 807-813, 2008.

[80] Y. A. M. Yusof, N. Ahmad, S. Das, S. Sulaiman, and N. A. Murad, "Chemopreventive efficacy of ginger (Zingiber officinale) in ethionine induced rat hepatocarcinogenesis," African Journal of Traditional, Complementary and Alternative Medicines, vol. 6, no. 1, pp. 87-93, 2008.

[81] R. Hu, P. Zhou, Y. B. Peng et al., "6-Shogaol induces apoptosis in human hepatocellular carcinoma cells and exhibits anti-tumor activity in vivo through endoplasmic reticulum stress," Plos One, vol. 7, no. 6, Article ID e39664, 2012.

[82] C. J. Weng, C. P. Chou, C. T. Ho, and G. C. Yen, "Molecular mechanism inhibiting human hepatocarcinoma cell invasion by 6-shogaol and 6-gingerol," Molecular Nutrition and Food Research, vol. 56, no. 8, pp. 1304-1314, 2012.

[83] E. P. Sabina, S. J. Pragasam, S. Kumar, and M. Rasool, “6-gingerol, an active ingredient of ginger, protects acetaminopheninduced hepatotoxicity in mice," Journal of Chinese Integrative Medicine, vol. 9, no. 11, pp. 1264-1269, 2011.

[84] H. Z. Huo, B. Wang, Y. K. Liang, Y. Y. Bao, and Y. Gu, "Hepatoprotective and antioxidant effects of licorice extract against $\mathrm{CCl}_{4}$-induced oxidative damage in rats," International Journal of Molecular Sciences, vol. 12, no. 10, pp. 6529-6543, 2011.

[85] A. Sharma and H. S. Rathore, "Prevention of acetaminophen induced hepatorenal damage in mice with rhizomes of Glycyrrhiza glabra. A histophysiological study," Ancient Science of Life, vol. 30, no. 3, pp. 72-77, 2011.

[86] E. Gumpricht, R. Dahl, M. W. Devereaux, and R. J. Sokol, "Licorice compounds glycyrrhizin and $18 \beta$-glycyrrhetinic acid are potent modulators of bile acid-induced cytotoxicity in rat hepatocytes," The Journal of Biological Chemistry, vol. 280, no. 11, pp. 10556-10563, 2005. 
[87] C.-H. Lee, S.-W. Park, Y. S. Kim et al., "Protective mechanism of glycyrrhizin on acute liver injury induced by carbon tetrachloride in mice," Biological and Pharmaceutical Bulletin, vol. 30, no. 10, pp. 1898-1904, 2007.

[88] J. Folkman, "Angiogenesis: an organizing principle for drug discovery?" Nature Reviews Drug Discovery, vol. 6, no. 4, pp. 273-286, 2007.

[89] P. Y. K. Yue, D. Y. L. Wong, P. K. Wu et al., “The angiosuppressive effects of 20(R)- ginsenoside Rg3," Biochemical Pharmacology, vol. 72, no. 4, pp. 437-445, 2006.

[90] P. Y. K. Yue, D. Y. L. Wong, W. Y. Ha et al., "Elucidation of the mechanisms underlying the angiogenic effects of ginsenoside Rgl in vivo and in vitro," Angiogenesis, vol. 8, no. 3, pp. 205-216, 2005.

[91] K. Zhang, J. Lu, T. Mori et al., "Baicalin increases VEGF expression and angiogenesis by activating the ERR $\alpha /$ PGC- $1 \alpha$ pathway," Cardiovascular Research, vol. 89, no. 2, pp. 426-435, 2011.

[92] S. M. Sagar, D. Yance, and R. K. Wong, "Natural health products that inhibit angiogenesis: a potential source for investigational new agents to treat cancer-part 2," Current Oncology, vol. 13, no. 3, pp. 99-107, 2006. 


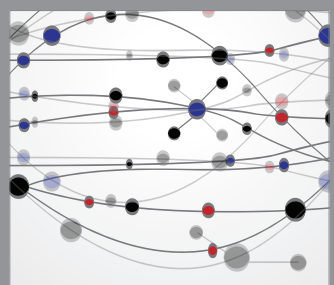

The Scientific World Journal
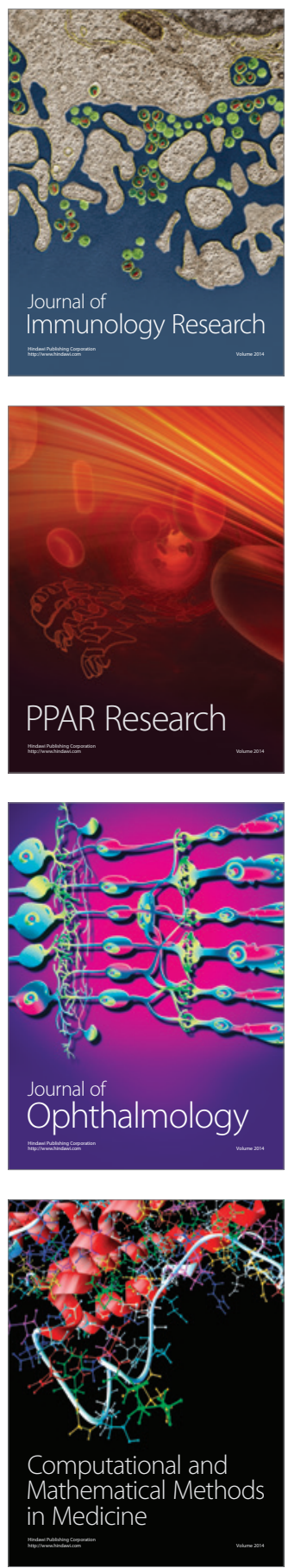

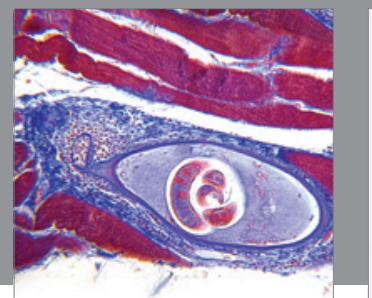

Gastroenterology

Research and Practice
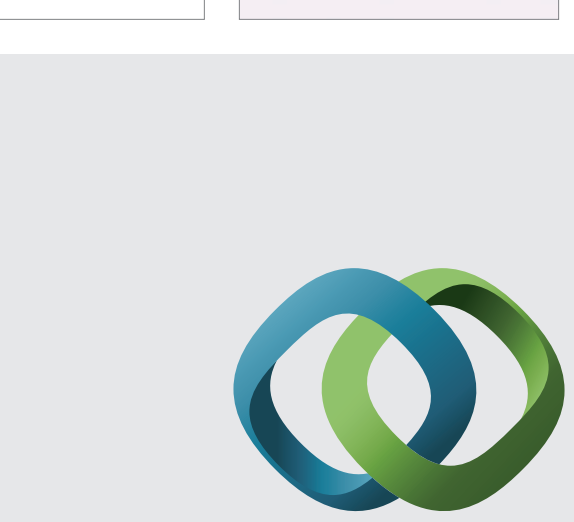

\section{Hindawi}

Submit your manuscripts at

http://www.hindawi.com
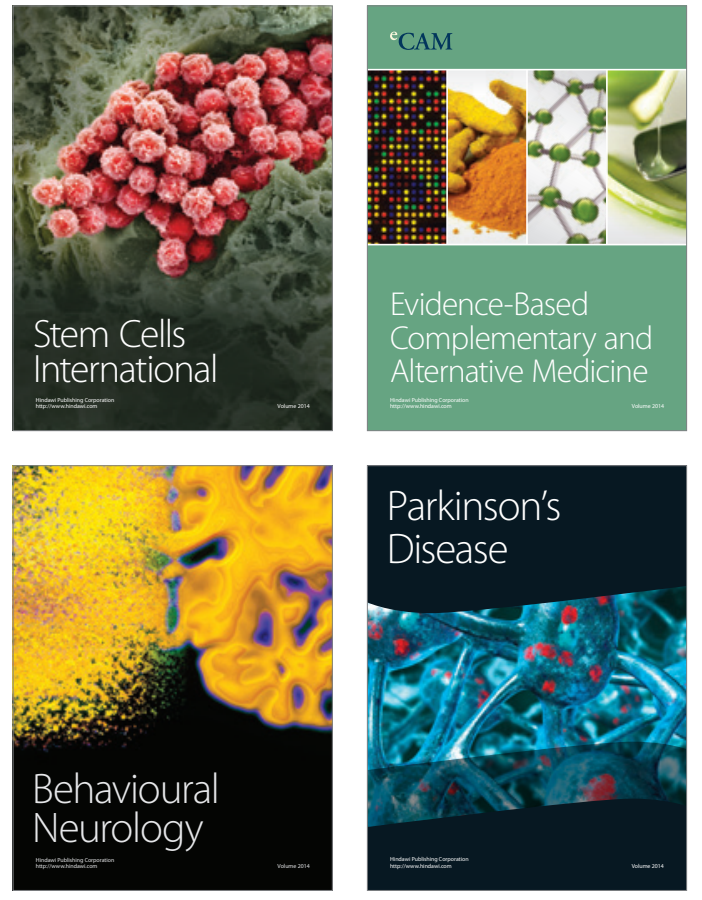
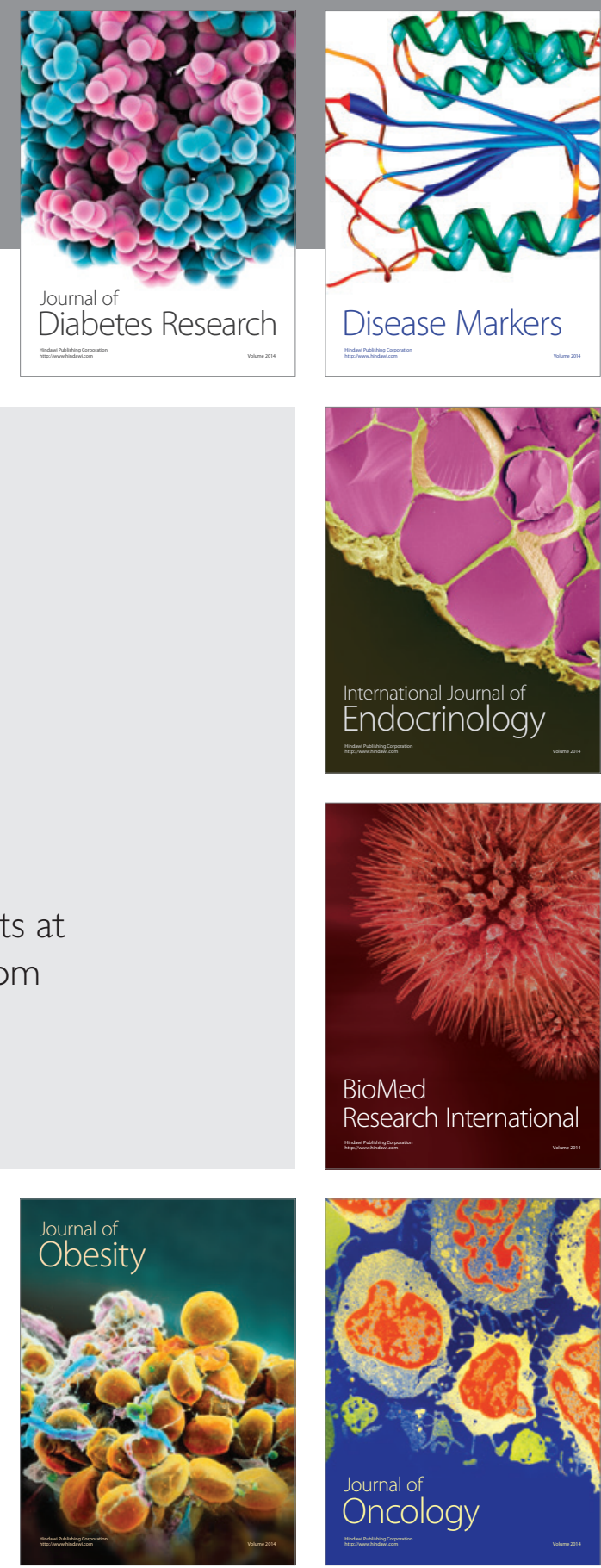

Disease Markers
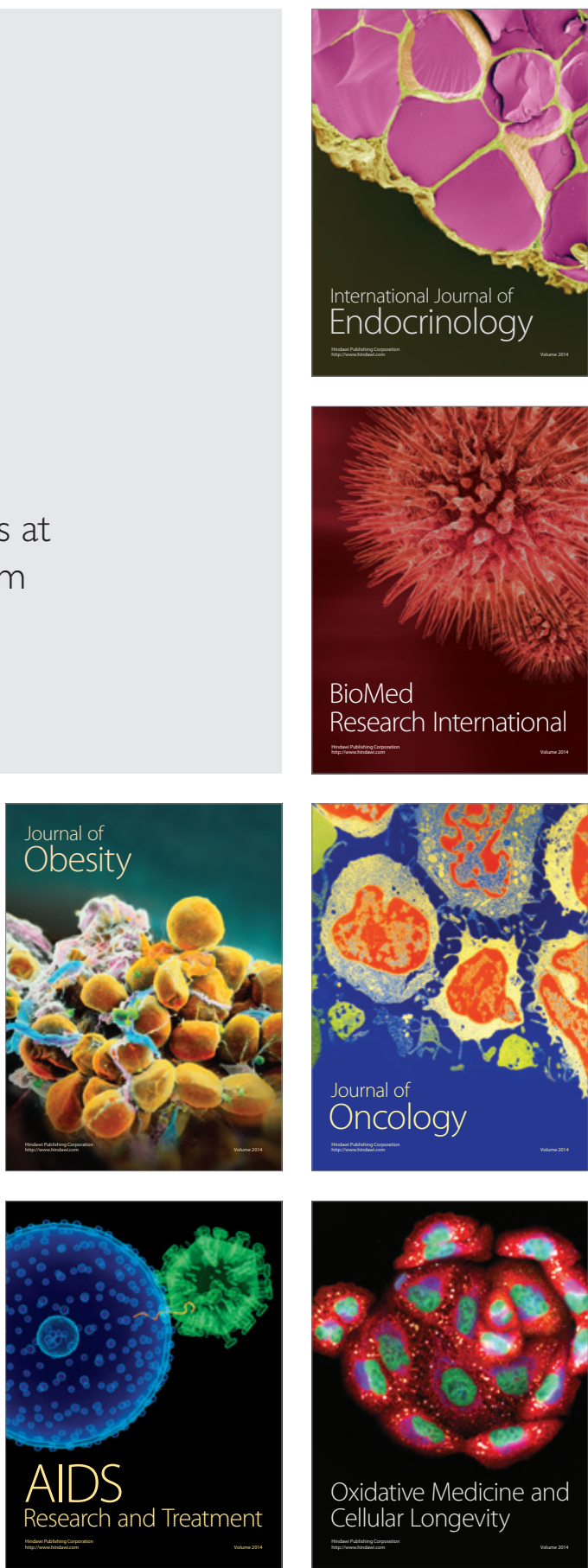